\title{
Hacia una revisión crítica de la recepción de Sor Juana Inés de la Cruz, desde el siglo diecisiete hasta la actualidad
}

\author{
VerónICA G Rossi*
}

Resumen:

El artículo plantea un recorrido por las diversas recepciones y lecturas que ha tenido la obra de Sor Juana Inés de la Cruz desde su siglo hasta nuestros días. G rossi revisa el discurso de los estudiosos en torno a ella, los olvidos y las interpretaciones reduccionistas tanto de su vida como de su obra. La restitución de la misma se ha fundamentado en vacíos del conocimiento sobre su época y su vida que la hermenéutica ha tratado llenar rebasando un sentido original inexistente. D espués de todo, cualquier trabajo no sólo de restitución sino también de interpretación está marcado por los supuestos ideológicos del sujeto que estudia. La propuesta es adoptar una perspectiva crítica diacrónica que analice los diferentes modos de leer a Sor Juana y su obra, para crear un balance en el diálogo con tal instancia y no caer en anacronismos.

Palabras clave:

Sor Juana Inés de la Cruz, recepción, lecturas anacrónicas, crítica feminista.

En su época y hasta recientemente, Sor Juana Inés de la Cruz era considerada una avis rara, un ser anómalo, exótico y hasta monstruoso. Ante todo una mujer que sacrificó sus virtudes femeninas,

${ }^{*}$ Universidad de Carolina del Norte. 
su natural inclinación al matrimonio, a la maternidad, a la abnegación, a la domesticidad y a la obediencia, para desarrollar un proyecto literario e intelectual excepcional que le otorgó celebridad internacional como Fénix Americana y D écima Musa. ${ }^{1}$

La crítica patriarcal ha leído su variada producción literaria como una biografía, como calco transparente de un cuerpo perecedero, frágil, violentado por el excesivo ejercicio del intelecto y condenado ineluctablemente al sacrificio y a la derrota. Esta visión reductora ha pervivido hasta nuestros días, a pesar de la riqueza estilística y semántica de sus textos y de diferentes hallazgos documentales como la Carta de M onterrey (1682), la Carta de Serafina de C risto (1 de febrero de 1691), los E nigmas ofrecidos a la Casa del Placer (1695), y el inventario de su celda que comprueban que la monja novohispana escribió, leyó y conversó con lucidos ingenios desde el recinto conventual. ${ }^{2}$ La creación literaria, que puede prescindir de la grafía material, según explica Alfonso Reyes, se manifiesta 0 adquiere primero su ser como ideación mental. D esde su encierro, Sor Juana viaja, compone y conoce con los pinceles abstractos de la fantasía. No hay limitaciones externas que puedan coartar esta inquebrantable vocación artística e intelectual.

La visibilidad pública y reconocimiento que alcanzó Sor Juana en sus días redundaron en "etiquetas de Fénix" (OC I 147, v167), deformadoras de su persona. En un romance al "Caballero recién llegado a Nueva España" (143-48), la voz poética vuelve explícita la otra cara de la vocinglera fama que llegó a tener la monja en España y en América: su cosificación en mercancía exótica que se exhibe y se explota.

${ }^{1}$ El proceso de mitificación de Sor Juana, el énfasis que han puesto sus lectores y comentadores en su naturaleza extraordinaria y su consecuente fijación en icono de la anomalía, ha sido ya ampliamente teorizado por críticas como Marie Cécilie Bénassy-Berling, Margo Glantz, Stephanie Merrim, Amanda Powell y Rosa Perelmuter.

${ }^{2}$ Sobre hallazgos relacionados con Sor Juana, véanse Alatorre, Alatorre y Tenorio, Schmidhuber, Tapia Méndez y Trabulse. 
En otro romance, con el epígrafe "En reconocimiento de las inimitables Plumas de la Europa" (158-61), la voz femenina ironiza los "panegíricos" (161, v. 94), "encomios" (v. 100) y "elogios mal empleados" (160, v. 68) de los "Ingenios" (v. 47) del mundo que proyectan una imagen prefabricada, un falso simulacro sobre su figura y su obra. La celebración de su talento extraordinario es una estrategia convalidadora de las estructuras patriarcales de poder que buscan subordinar el pensamiento y la agencia política de la mujer. La rareza y anormalidad de su condición femenina, propensa contra natura al ejercicio del intelecto, es entonces objeto de maravilla y de admiración. La perfección y pluralidad de su obra quedan así relegadas a segundo plano:

Vosotros me concebisteis

a vuestro modo, y no extraño

lo grande: que esos conceptos

por fuerza han de ser milagros.

La imagen de vuestra idea

es la que habéis alabado;

y siendo vuestra, es bien digna

de vuestros mismos aplausos.

Celebrad ese, de vuestra

propia aprehensión, simulacro,

para que en vosotros mismos

se vuelva a quedar el lauro.

Si no es que el sexo ha podido

0 ha querido hacer, por raro,

que el lugar de lo perfecto

obtenga lo extraordinario;

(161, vv. 109-124)

La abierta afirmación de la diferencia y distancia de la voz poética del poema frente a este icono uniformador, creado por las plumas de su tiempo, tiene también relevancia para quien hoy día lee sus obras. Todavía hoy se siguen proyectando imágenes simplificadoras sobre la inagotable diversidad de sus escritos: 


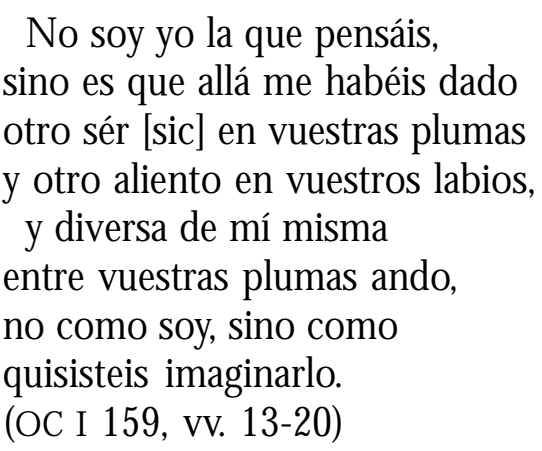

Un breve recorrido por las diferentes corrientes de recepción de la obra de Sor Juana nos permite apreciar el creciente interés crítico y artístico por esta insigne poeta y pensadora, lo cual ha abierto nuevos espacios para la profundización del conocimiento de su obra y de su mundo así como para la institucionalización de su figura en icono cultural.

Después de haber gozado del interés y de la admiración de un amplio público a lo largo del siglo dieciocho, las obras de Sor Juana caen en el olvido. D urante gran parte de los dos siglos posteriores a su muerte, la caricaturización peyorativa de sus escritos, como muestra Perelmuter, está basada en el desconocimiento de sus textos. La visión negativa de la monja mexicana es producto de la aversión generalizada hacia el barroco que predomina en estos siglos, un legado iluminista. En México, además, historiadores liberales decimonónicos conciben el periodo colonial como una etapa oscurantista de la historia nacional en la que el país se rezaga ante los avances de la modernidad y se anquilosa a causa de la hegemonía de la Iglesia Católica. De esta manera, en pluma de escritores mexicanos como José María Vigil, Ignacio Ramírez, E 1 N igromante e Ignacio Altamirano, Sor Juana pasa a ser una doble aberración como monja colonial y escritora barroca. En una carta dirigida a una poeta (1871), Altamirano dice sobre Sor Juana: "No seré yo quien recomiende a Ud., a nuestra Sor Juana Inés de la Cruz, nuestra D écima Musa, a quien es necesario dejar quietecita en el fondo de su sepulcro y entre el pergamino de sus libros" (citado por Méndez Plancarte, Sueño xvii). No es sino hasta 1873 que se publica un 
volumen de las 0 bras Selectas de la ólebre Monja de Méxioo (Quito: Imprenta Nacional), recopiladas por el escritor ecuatoriano Juan León Mera, "señal del creciente interés en el conocimiento de la obra de la 'Monja de México' " (Perelmuter 101). D urante el último cuarto del siglo diecinueve, aumentan las antologías y ediciones modernas de los textos sorjuaninos (124).

Según Paz, A mado Nervo enciende la "chispa del reconocimiento" de Sor Juana en México con su libro Juana de A sbaje (1910) (trampas 11). Entre 1910 y 1930 se desentierran y fijan textos (11). A partir de la revaloración de la poesía de Luis de Góngora que promueve la generación del veintisiete, renace también un interés por restitutir el valor literario e histórico de la obra de Sor Juana. D e los años veinte a los cincuenta, poetas, académicos y pensadores se avocan a la profundización del estudio de sus textos: Alfonso Reyes, Pedro Henríquez Ureña, D orothy Schons, Ermilo Abreu Gómez, los poetas de Contemporáneos como Jorge Cuesta, X avier Villaurrutia y José G orostiza, Ezequiel A. Chávez, Eunice Joiner Gates, Enrique Díez-Canedo, Karl Vossler, Ludwig Pfandl, Clara Campoamor, G abriela Mistral, Manuel Toussaint, Francisco López Cámara, Anita Arroyo, D orothy Clotelle Clark, Alicia Sarre, Jesús Reyes Ruiz, Julio Jiménez Rueda, Francisco de la Maza, Irving Leonard y Robert Ricard. ${ }^{3}$

Entre todo este grupo, destaca la labor monumental de Alfonso Méndez Plancarte, cuya edición crítica de las 0 bras completas de Sor Juana con prólogos y notas, salida a la luz entre 1951 y 1957, con motivo de la celebración del tercer centenario del nacimiento de Sor Juana, todavía no ha sido superada. ${ }^{4}$ La edición comentada de Méndez Plancarte establece una sólida base para el despegue de indagaciones iluminadoras sobre diferentes aspectos de la obra de Sor Juana.

\footnotetext{
${ }^{3}$ Perelmuter dedica un capítulo de su libro a "Las pioneras de la crítica sorjuanina" (límites 137-46).

${ }^{4}$ A la muerte del erudito jesuita, Alberto G. Salceda edita el cuarto y último volumen de las 0 bras completas.
} 
O tra pléyade de estudiosos surge en los setenta: G iuseppe Bellini, José Gaos, Sergio Fernández, Luigi Fiorentino, Gerand Cox Flynn, Jaime Labastida, María E. Pérez, Ramón Xirau y Francisco M. Zertuche. Más recientemente, críticos como Antonio Alatorre, Marie Cécile Bénassy-Berling, Mauricio Beuchot, D olores Bravo Arriaga, Giuseppe Bellini, Jean Franco, Margo Glantz, José Pascual Buxó, O ctavio Paz, Rosa Perelmuter, Dario Puccini, G eorgina Sabat de Rivers, Guillermo Schmidhuber y Elías Trabulse, emprenden la tarea de ilustrar, ante un amplio público, la complejidad retórica, simbólica e ideológica del corpus sorjuanino desde una rica variedad de acercamientos historicistas, filológicos, feministas, textuales, semióticos, filosóficos y culturales.

Las interpretaciones feministas de la obra de Sor Juana que inaugura la profesora norteamericana D orothy Schons y que G eorgina Sabat de Rivers ha encabezado con una vasta obra crítica fundamentada en su erudición así como en un cuidadoso trabajo textual y de archivo, constituyen la fuente de los nuevos campos de investigación sobre la monja que buscan situar su vida y su obra, su agencia femenina, en un contexto cultural específico. El corpus crítico de Sabat de Rivers sienta la base para la realización de otros estudios señeros sobre la obra de Sor Juana como los de Electa Arenal, Emilie Bergmann, Jorge Checa, Linda Egan, Susana Hernández Araico, Frederick Luciani, Alessandra Luiselli, Yolanda Martínez-San Miguel, Stephanie Merrim, Mabel Moraña, Sara Poot Herrera y Nina M. Scott.

La restitución histórica y cultural de Sor Juana se apoya en gran medida en las valiosas contribuciones que críticos latinoamericanos, norteamericanos y europeos han hecho al campo de los estudios de monjas y mujeres de la temprana modernidad. Las investigaciones fundacionales de Josefina Muriel y Asunción Lavín se aúnan a trabajos seminales posteriores, como el libro Untold Sisters de Arenal y Schlau, que son fuente de consulta obligada para situar a Sor Juana en un entorno sociocultural, institucional e histórico preciso, compuesto de una comunidad de monjas y mujeres creadoras. Por oposición a las interpretaciones aisladas, descontextualizadas, que colocan a la monja novohispana en el vacío de la excepciona- 
lidad, los estudios sorjuaninos basados en este campo de investigación interdisciplinario relacionan los tópicos retóricos y filosóficos de su obra con una tradición literaria, filosófica y cultural femenina.

La crítica feminista de la obra de Sor Juana busca responder a la pregunta clave que formuló Stephanie Merrim en el prefacio de su histórica colección de ensayos Feminist Perspectives on Sor Juana Inés de la Cruz (1991): "What did it mean for Sor Juana to be a woman writer and a woman writing?" (7). Siguiendo las huellas de Sabat de Rivers y de Schons, esta compilación de ensayos estudia "the personal and intellectual climate in which Sor Juana lived and wrote, as well as each of the genres in which she employed her literary talents" (7). Es decir, busca situar en un marco cultural definido y desde un punto de vista feminista o centrado en el signo de lo femenino, las aportaciones literarias de Sor Juana. Esto representa un alejamiento del interés puramente biográfico, aislado de todo contexto retórico-cultural que tenía Sor Juana para la crítica tradicional patriarcal, como ya mencionamos anteriormente.

En su obra Sor Juana Inés de la Cruz o las trampas de la fe, un compendio enciclopédico de historia, biografía y crítica literaria, O ctavio Paz sigue el modelo de D orothy Schons al intentar colocar la vida y la obra de la monja en la sociedad novohispana de la segunda mitad del siglo diecisiete, con base en documentos, libros y crónicas de su tiempo (trampas 15; Sabat de Rivers, "Biografías" 931). Sin embargo, Paz no abandona el modelo psicoanalítico patriarcal del profesor alemán Ludwig Pfandl, quien describió a Sor Juana como una "neurótica, en la que predominan fuertes tendencias masculinas" y cuya "fijación de la imagen paternal" la lleva al "narcisimo" (13). Según este crítico mexicano, Sor Juana mata simbólicamente al padre y asume el rol masculino asociado al universo del conocimiento al que fue introducida a través de la biblioteca de su abuelo. La escritora vive una doble masculinización y feminización: toma el lugar de la madre y transfiere su instinto maternal y amoroso a la creación mental. Al igual que otros críticos, Paz interpreta la obra de la monja como reflejo biográfico de una búsqueda hacia el conocimiento que termina en derrota política e intelectual. Al final del capítulo titulado "La abjuración" escribe Paz: 
La fe y las creencias de Sor Juana fueron cómplices de su derrota. Regaló sus libros a su persecutor, castigó su cuerpo, humilló su inteligencia y renunció a su don más suyo: la palabra. El sacrificio en el altar de Cristo fue un acto de sumisión ante prelados soberbios. En sus convicciones religiosas encontró una justificación de su abjuración intelectual: los poderes que la destrozaron fueron los mismos que ella había servido y alabado. (608)

Seducido por el enigma de su cuerpo, Paz resalta la "doble singularidad" (15) de Sor Juana o su "excepción [. . .] insoportable" (556), ya sea "la de su vida y la de su obra" (15) o "la de su sexo y la de su superioridad intelectual" (556). A pesar de señalar que el interés biográfico por Sor Juana ha redundado en interpretaciones como las de Calleja y Pfandl, que impregnan su objeto de estudio del discurso hagiográfico y psicoanalítico respectivamente, y en el que la misma obra literaria "se evapora" (12), Paz admite su "seducción" tanto intelectual como sensual por la monja y se pregunta: "¿por qué escogió, siendo joven y bonita, la vida monjil?; ¿cuál fue la verdadera índole de sus inclinaciones afectivas y eróticas?" (12-13). Por el contrario, las nuevas líneas de investigación sobre la monja novohispana, sustentadas en estudios historicistas y/ o feministas como los de Arenal, Bénassy-Berling, Franco, Merrim, Perelmuter, Sabat de Rivers, Trabulse y otros más, se alejan de un acercamiento sexual o biográfico para relevar dentro de la pluralidad de sentidos que erigen los textos sorjuaninos la representación simbólico-alegórica del valor positivo de la intelección y creación femeninas. Para estos críticos, la obra de Sor Juana no escenifica la renuncia, el fracaso, la capitulación ante el poder, el silenciamiento, la enfermedad y la muerte sino la afirmación del poder intelectual y político de la mujer; en particular, su derecho inalienable al conocimiento, a la interpretación y a la participación en la sociedad.

Estudios recientes sobre Sor Juana exponen las premisas ideológicas que cimientan los diferentes intentos de recuperación de su figura y de su obra. Enrico Mario Santí desarrolla un detallado análisis de los resortes políticos y retóricos implícitos en el estudio de 
Paz para concluir que las políticas de restitución constituyen el meollo de la recepción institucional de Sor Juana (102-03). Para el crítico cubano, esta práctica hermenéutica tiene un carácter suplementario que excede más que restaura un sentido original inexistente (la figura histórica de Sor Juana, el sentido definitivo, coherente de su escritura) (104). Santí concuerda con Schons y Sabat de Rivers al apuntar que las diferentes restituciones de Sor Juana se fundamentan en una serie de lagunas sobre nuestro conocimiento de su vida y de su tiempo (118).

Toda restitución está anclada en los supuestos ideológicos del sujeto de la interpretación. Por lo mismo, es imposible articular una visión completa y perentoria de Sor Juana como sujeto histórico así como del significado o significados de su obra (119). Sin embargo, lo que afirma Santí es aplicable a la obra (y vida) de todo escritor, incluso del presente. ¿Es posible reconstruir una vida o sentido concluyente a partir de marcas textuales temporales, de carácter irrevocablemente fragmentario? Es una pregunta que nace de cuestionamientos deconstruccionistas contemporáneos. Sin embargo, la advertencia de Santí nos permite colocar en una perspectiva crítica las categorizaciones absolutistas y anacrónicas sobre Sor Juana, excesos interpretativos que las mismas voces de sus textos controvierten.

Las vicisitudes de Sor Juana mencionadas en la Respuesta y la biografía de la monja que incluye Calleja en su "Aprobación" de Fama y obras póstumas (1700) han sido y siguen siendo fuentes muy frecuentadas en la creación del icono popular de Sor Juana. En él, la figura autorial de Sor Juana, reconstruida a partir de fragmentos, desplaza la riqueza estilística y polisémica de su obra. El fuerte interés en el sujeto histórico es comprensible ya que la vida de la monja, aun cuando escasamente documentada, da cuerpo a una agencia femenina colonial que se sobrepone a los silencios, tachados y omisiones de la historia patriarcal. Sin embargo, es necesario volver explícita la base imaginaria, a la vez que ideológica, de estas reconstrucciones biográficas.

De gran relevancia para nuestra comprensión de Sor Juana y de su mundo es reconocer su excelencia como poeta. La monja 
novohispana alcanzó fama internacional y actuó en el terreno público de la cultura, reservado a los hombres, gracias al apoyo que recibió de otras mujeres, como la condesa de Paredes, y también por ser sagaz política, brillante intelectual y ante todo, por ser una gran poeta. Para Alatorre, "donde Sor Juana compitió y triunfó fue en el vasto anfiteatro de la poesía española ("Avances" 660, énfasis en el original). También de la americana y del mundo. Prueba de la riqueza inagotable de su escritura es la energía con la que ha sido y sigue siendo actualizada. Sor Juana continúa viva, vigente para lectores y espectadores, a través de nuestras interpretaciones. De ahí los grandes beneficios que han brindado las variadas restituciones de su obra.

En el campo de la creación, la figura y obra de Sor Juana inspira la composición de un sinfín de obras literarias y artísticas: poemas, obras de teatro, novelas, telenovelas, performances, dibujos, pinturas, grabados y películas. Particularmente profuso ha sido el debate teórico y creador generado por críticas y artistas chicanas en torno a este sujeto histórico y a su obra polifacética. En este terreno, se hace de Sor Juana un icono fundacional de la cultura femenina y del feminismo chicanos. Por su condición marginal, identidad híbrida, afirmación como mujer intelectual además de las múltiples dimensiones sociales y políticas de su obra, Sor Juana es considerada una precursora (foremother) chicana y feminista. Para estas mujeres latinas la monja mexicana es modelo de actuación política, resistencia cultural y subversión de estructuras patriarcales e imperiales.

En este somero panorama de los estudios sorjuaninos aprovecho la oportunidad para recalcar la importancia de ampliar el diálogo entre los diferentes campos de investigación y creación sobre la vida y obra de la monja mexicana. El rescate de la figura de Sor Juana, su apropiación o restitución a través de diferentes lentes ideológicos, abre nuevos espacios para la invención de nuevas formas de arte y de pensamiento. Por otro lado, quedan por analizar las dinámicas interpretativas anacrónicas que redundan en una visión uniforme, sistemática de su obra, al subrayar, entre otras cosas, el carácter transgresor, contestatario de todos sus escritos, sin excepción, acorde con un populismo romántico, un (proto)nacionalismo 
liberal o revolucionario, una modernidad emancipatoria así como un multiculturalismo posmoderno. A partir de una perspectiva crítica de los supuestos que organizan las narraciones que forman parte de las diferentes estrategias de apropiación de Sor Juana desde su época a nuestros días podemos entablar un diálogo balanceado entre la obra y nuestra propia circunstancia.

\section{Bibliografía}

Alatorre, Antonio. "Avances en el conocimiento de Sor Juana." Conquista y contraconquista: la escritura del $\mathrm{N}$ uevo $\mathrm{M}$ undo, A ctas del X X V III C ongreso del Instituto Internacional de L iteratura Iberoamericana. Eds. Julio Ortega y JoséAmor. Mexico/ Providence, Rhode Island: El Colegio de México-Brown University, 1994. 659-67. edición y estudio. E nigmas ofrecidos a la casa del plaœer. México: El Colegio de México, 1995.

y Martha Lilia Tenorio. Serafina y Sor Juana (con tres apéndios). México: El Colegio de México, 1998.

Arenal, Electa y Stacey Schlau. Untold Sisters, $\mathrm{H}$ ispanic N uns in Their

0 wn W orks. Translations by Amanda Powel, Albuquerque, NM: U of New Mexico, 1989.

Cruz, Sor Juana Inés de la. A utodefensa espiritual, Carta de la Madre Juana Inés de la Cruz escrita al Rev, P, Maestro A ntonio $\mathrm{N}$ únez de la Compañía de Jesús. Ed. Aureliano Tapia Méndez. Monterrey, México: Impresora Monterrey, 1986.

.E nigmas ofrecidos a la casa del placer, Antonio Alatorre (ed. y estudio). México: El Colegio de México, 1995.

. Fama y obras póstumas, ed., facsimilar de la de Madrid, 1700, a cargo de G abriela Eguía-Lis Ponce, Intro, Antonio Alatorre. México: Facultad de Filosofía y Letras, Universidad Nacional Autónoma de México, 1995.

. O bras completas, ed., prólogo y notas Alfonso Méndez Plancarte, Vols. 1-3. México: Fondo de Cultura E conómica, 1988, 1994, 1994. 
. 0 bras ompletas, ed., intro, y notas Alberto G. Salceda, Vol,

4. México: Fondo de Cultura Económica, 1994.

. El Sueño. Edición, introducción, prosificación y notas de

Alfonso Méndez Plancarte. México: UNAM, 1989.

Méndez Plancarte, Alfonso, ed. E 1 Sueño de Sor Juana Inés de la Cruz.

México: UNAM, 1989.

Merrim, Stephanie. Feminist Perspectives on Sor Juana Inés de la Cruz.

Wayne State U P, 1991.

Paz, O ctavio. Sor Juana Ines de la Cruz o las trampas de la fe. México:

Fondo de Cultura Económica, 1988.

Perelmuter, Rosa. L os límites de la femineidad en Sor Juana Inés de la

C ruz: E strategias retóricas y recepción literaria. Madrid-Frankfurt:

ervuert-Iberoamericana, Biblioteca Áurea Hispánica, 2004.

Sabat de Rivers, G eorgina. "Biografías: Sor Juana vista por D orothy

Schons y O ctavio Paz." E studios de literatura hispanoamericana, Sor

Juana Inés de la Cruz y otros poetas barrooos de la colonia. Barcelona:

Promociones y Publicaciones Universitarias, 1992. 327-39.

Santí, Enrico Mario. "Sor Juana, Octavio Paz and the Poetics of

Restitution." Indiana Journal of $\mathrm{H}$ ispanic L iteratures 1, 2 (Spring 1993): 101-39.

Schmidhuber de la Mora, Guillermo. "Hallazgo de dos obras perdidas de Sor Juana Inés de la Cruz: la comedia La segunda Celestina y una Protesta de Fé." Mairena 16, 39 (1995): 105-16. . "Hallazgo y significación de un texto en prosa perteneciente a los últimos años de Sor Juana Inés de la Cruz." H ispania 76 (1993): 189-96.

"Las obras perdidas de Sor Juana Inés de la Cruz y dos hallazgos." Memorias del Congreso Internacional, Coord. Beatriz López Portillo. México: Universidad del Claustro de Sor JuanaUNESCO-Fondo de Cultura Económica, 1998, 410-17.

Tapia Méndez, Aureliano. A utodefensa espiritual, Carta de la Madre Juana Inés de la Cruz escrita al Rev, P, Maestro A ntonio N úñez de la Compañía de Jesús. Monterrey, México: Impresora Monterrey, 1986. Trabulse, Elías. L os años finales de Sor Juana: U na interpretación (1688695). México: CONDUMEX, 1995. 
HaCia una Revisión cRítica de la Recepción de Sor Juana Inés de la Cruz 63

. Introduction \& paleographic transcription, Carta a Seraphina de Christo, 1691. Los Angeles: Aldan, 1997.

. Introduoción y transcripción paleográfica, C arta de Serafina de C risto, 1691. E dición facsimilar, Toluca: Biblioteca Sor Juana Inés de la Cruz, 1996. 